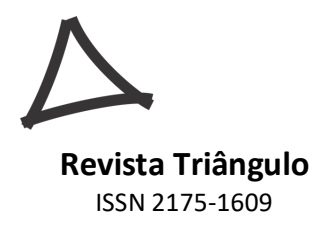

\title{
ESTRESSE E ESTRATÉGIAS DE ENFRENTAMENTO DE PROFESSORES: UM ESTUDO COMPARATIVO
}

\author{
STRESS AND COPING OF TEACHERS: A COMPARATIVE STUDY \\ ESTRÉS Y ESTRATEGIAS DE ENFRENTAMIENTO DE PROFESORES: UN ESTUDIO \\ COMPARATIVO
}

Tatiane Lebre Dias

Universidade Federal de Mato Grosso (UFMT) E-mail: tatianelebre@gmail.com

Maelison Silva Neves

Universidade Federal de Mato Grosso (UFMT) E-mail: maelison@gmail.com

Kelly Ambrozio Silveira

Universidade Federal do Espírito Santo (UFES) E-mail: kellyasfs@gmail.com

Sônia Regina Fiorim Enumo

Pontifícia Universidade Católica de Campinas. E-mail: sonia.enumo@gmail.com

\begin{abstract}
RESUMO
Este trabalho investigou os indicadores de estresse ocupacional e as estratégias de enfrentamento como processos de prevenção e intervenção de professores do ensino fundamental do Espírito Santo (ES) e professores da rede de educação profissional e tecnológica de Mato Grosso (MT). No estudo, participaram 190 professores (109 do Espírito Santo e 81 de Mato Grosso), com predominância do sexo feminino (82,1\%), que responderam uma escala específica sobre estresse no trabalho docente e sobre estratégias de enfrentamento. De modo geral, verificou-se maior percentual de professores que não indicaram presença de estresse (ES=84,4\%; $\mathrm{MT}=85,2 \%$ ). As estratégias de enfrentamento mais utilizadas pelos professores foram: a) o quanto têm praticado: esquecer as coisas que aconteceram na escola, após o período de trabalho e viver uma vida saudável; b) o quanto é efetivo: analisar e tentar manter os problemas em foco. Comparativamente, os professores do ES apresentaram mais estratégias de enfrentamento. $\mathrm{O}$ uso de estratégias de enfrentamento diante das condições adversas encontradas pelos professores é um tema que precisa ser mais investigado com objetivo de melhorar a qualidade de vida e as condições de trabalho docente.
\end{abstract}

PALAVRAS-CHAVE: Estresse ocupacional. Educação profissional. Professores.

\begin{abstract}
This work investigated the occupational stress indicators and coping as a process of prevention and intervention of teachers of elementary education in Espirito Santo (ES) and teachers of the professional and technological education network of Mato Grosso (MT). The study was attended by 190 teachers (109 from Espirito Santo and 81 from Mato Grosso), predominantly female (82.1\%) who responded to a specific scale on teacher work stress and another on coping strategies. In general, the percentage of teachers who did not indicate the presence of stress was higher $(E S=84.4 \%, M T=85.2 \%)$. The coping most used by the teachers were: a) to what they have practiced: forget the things that happened in school, after the period of work and live a healthy life; b) how effective it is: to analyze and try to keep problems in focus. Comparatively ES teachers presented more coping strategies. The use of coping in the face of adverse conditions encountered by teachers is an issue that needs to be further investigated in order to improve the quality of life and the working conditions of teacher.
\end{abstract}

KEYWORDS: Occupational stress. Professional education. Teachers.

\section{RESUMEN}

Este trabajo investigo los indicadores de estrés ocupacional y lãs estrategias de enfrentamiento como proceso de prevención e intervención de profesores de La enseñanza fundamental Del Espírito Santo y profesores de La 


\section{Revista Triângulo}

ISSN 2175-1609

red de educación profesional y tecnológica de Mato Grosso (MT). Em el estúdio participaron 190 profesores (109 de Espírito Santo y 81 de Mato Grosso), con predominio del sexo femenino (82,1\%), que respondieron a una escala específica sobre estrés em el trabajo docente y otra sobre estrategias de enfrentamiento. En general, se verificó mayor el porcentaje de profesores que no indicaron presencia de estrés $(E S=84,4 \%, M T=85,2 \%)$. Las estrategias de enfrentamiento más utilizadas por los profesores fueron: a) cuánto ha practicado: olvidar las cosas que sucedió em la escuela, después del periodo de trabajo y, vivir una vida saludable; b) cuanto es efectivo: analizar e intentar mantener los problemas en foco. Em comparación, los profesores del ES presentaron más estrategias de enfrentamiento. El uso de estrategias de enfrentamiento ante las condiciones adversas encontradas por los profesores es un tema que necesita ser más investigado con el objetivo de mejorar la calidad de vida y las condiciones de trabajo docente.

PALABRAS-CLAVE: Estrés ocupacional. Educación profesional. Maestros

\section{INTRODUÇÃO}

Nos últimos anos na área educacional, é expressivo o número de investigações a respeito da saúde física e mental do professor. Isso ocorreu a partir de publicações que passaram a revelar/denunciar o estado de saúde dos professores, em face dos afastamentos das atividades profissionais, decorrentes de transtornos mentais e comportamentais (SOUZA, 2013; MOTA, 2011).

Os problemas de saúde dos trabalhadores da educação, desde o final da década de 1990, já expressam sinais de preocupação. De acordo com a Confederação Nacional dos Trabalhadores em Educação (CNTE), em pesquisa desenvolvida no ano de 1999, com 52 mil entrevistados, atuando em 1440 escolas dos 26 estados brasileiros e o Distrito Federal, revelou que quase metade (48\%) sofria de algum sintoma da síndrome de Burnout (CNTE, 2008). No que se refere à Síndrome de Burnout, a definição mais referenciada na área baseiase na perspectiva social-psicológica de Christina Maslach e colaboradores. A respeito dessa definição, Carlotto (2002, p. 23), amparada pelos autores clássicos da área, define como "um tipo de estresse ocupacional que acomete profissionais envolvidos com qualquer tipo de cuidado em uma relação de atenção direta, contínua e altamente emocional". Nessa perspectiva teórica, a síndrome é constituída por três dimensões, a saber: exaustão emocional, despersonalização e baixa realização pessoal no trabalho. As características da Síndrome apresentam consequências nos níveis individual e organizacional para o trabalho, assim, compreendê-la melhor enquanto fenômeno psicossocial nos permitirá identificar "suas etapas e dimensões, seus estressores mais importantes, seus modelos explicativos, podemos vislumbrar ações que permitam prevenir, atenuar ou estancar" (CARLOTTO, 2002, p. 27). 


\section{Revista Triângulo}

ISSN 2175-1609

\section{REFERENCIAL TEÓRICO}

Em 2004, numa investigação que envolveu 10 estados brasileiros, verificou-se que $30,4 \%$ dos entrevistados (professores e funcionários) nas escolas relataram problemas de saúde relacionados à síndrome de Burnout e ainda, 22,6\% relataram a necessidade de licenças temporárias ou definitivas do trabalho (CNTE, 2008). Mais recentemente, uma pesquisa desenvolvida pela Universidade de Brasília, com mais de 8 mil professores da região CentroOeste, revelou sintomas como baixa realização profissional $(31,2 \%)$, alto grau de esgotamento emocional (quase 30\%) e distanciamento dos alunos (14\%), o que mostra que 15 em cada 100 professores apresentam sintomas da síndrome de Burnout, embora muita gente desconhece os sintomas (CNTE, 2008).

Uma das causas investigadas para esses números e que se mostra presente como variável investigada, refere-se à precarização do trabalho docente. Um primeiro aspecto desse panorama diz respeito às influências da lógica capitalista e mercadológica que modificam as relações de trabalho no interior das instituições de ensino, das políticas educacionais e da regulação da educação pública, por exemplo, no ensino superior (SILVA, 2008; MAUES; MOTA JUNIOR, 2011; VIANA; MACHADO, 2016).

Nas escolas públicas brasileiras, de modo geral, o cenário de precarização também se faz presente, conforme relata Oliveira (2004, p. 1132), diante das exigências a que o professor tem que assumir: "Muitas vezes esses profissionais são obrigados a desempenhar funções de agente público, assistente social, enfermeiro, psicólogo, entre outras”. De acordo com a autora, esses processos têm sido aceitos e se agravado, porém, pouco se tem discutido sobre eles.

Em relação ao estresse, estudos mais recentes abordam seus diferentes aspectos, considerando se tratar de um conceito amplo. Em recente revisão sistemática da literatura sobre o estresse entre os anos de 1959 a 2014, Nodari et al (2014, p. 61) verificaram uma “influência multifatorial no padrão e na magnitude das respostas ao estresse, com predomínio nas manifestações de sintomas psicológicos”. Assim, a forma como o indivíduo lida com as experiências e os eventos estressores são aspectos a serem considerados em relação à vulnerabilidade do organismo para o surgimento de doenças físicas e psicológicas (NODARI et al., 2014). 


\section{Revista Triângulo}

ISSN 2175-1609

Nessa perspectiva, numa abordagem mais recente sobre o estresse, Aldwin (2007, p. 24) enfatiza que "estresse se refere àquela qualidade de experiência, produzida por uma transação pessoa-ambiente, que, através tanto da excitação ou recrudescimento, resultam em estresse psicológico ou fisiológico". Ainda com o objetivo de compreender o sentido do termo estresse, Mazon (1975 apud Aldwin, 2007) identificou três formas pelas quais o estresse tem sido compreendido: 1) um estado interno do organismo, às vezes, referido como “tensão"; 2) um evento externo; 3) uma experiência que desponta de uma transação entre a pessoa e o ambiente. De acordo com Aldwin (2007), os estressores, isto é, as fontes externas ao estresse, podem ser físicas, que incluem trauma, condições ambientais aversivas ou socioculturais relacionados aos eventos da vida como produto da estrutura social.

A explicação para a forma como o indivíduo supera ou enfrenta as condições adversas que geram estresse encontra-se nos estudos sobre estratégias de enfrentamento (coping). Recentemente, Ramos et al (2015, p. 270) apresentaram as três grandes abordagens sobre o coping, sendo “(a) coping como estilos hierárquicos e centrados em mecanismos de defesa e estilos de personalidade, em uma abordagem psicodinâmica; (b) coping como processo de interação indivíduo-ambiente ou perspectiva cognitiva do coping (...)". De acordo com Ramos et al (2015), na primeira abordagem, o coping foi relacionado a autores da Psicologia do Ego, na formulação psicanalítica do desenvolvimento humano e dos seus conceitos. A segunda abordagem tem como precursor o estudo de R. S. Lazarus com a obra "Psychological Stress and Coping Process" no ano de 1966, na qual o coping é compreendido "como um processo resultante de uma transação entre o indivíduo e o ambiente, buscando seus determinantes situacionais e cognitivos" (RAMOS et al, 2015, p. 271).

A última abordagem “(...) (c) coping como ação regulatória, em uma perspectiva desenvolvimentista" (RAMOS et al., 2015, p. 270), baseia-se nos estudos de Skinner et al (2003), a partir da Teoria Motivacional do Coping (TMC), na qual a forma como o indivíduo lida com as situações estressantes envolve regulação de comportamentos, emoção, atenção e motivação. Nessa teoria, de acordo com Ramos et al (2015, p. 272), “O coping é desencadeado, para a TMC, quando uma dada experiência é percebida pelo sujeito como ameaça ou desafio a alguma de suas necessidades psicológicas básicas ou a várias delas".

Partindo dessas perspectivas teóricas sobre estresse e coping compreende-se que as condições de trabalho, principalmente, as do professor em função do cenário precarizado, 


\section{Revista Triângulo}

ISSN 2175-1609

tornam-se geradores de estresse. Com base em teóricos da área sobre estresse ocupacional, Souza e Araujo (2015, p. 92) esclarecem que estresse ocupacional "pode ser compreendido como um complexo processo em que o trabalhador busca responder a demandas que ultrapassam as possibilidades de adaptação individual e social, desencadeando-se transtornos no plano biológico e/ou comportamental".

Desse modo, o estresse docente e as estratégias de enfrentamento passaram a ser objeto de investigação na literatura nacional (VIEIRA et al, 2016; FERREIRA et al, 2015; SANTOS, 2009).Essa temática é investigada por Chris Kyriacou que, a partir de uma revisão da literatura, salientou que os estudos devem ter como preocupações futuras: monitorar as reformas educacionais como prováveis geradoras de estresse; explorar as formas como alguns professores conseguem negociar com sucesso os períodos de reavaliação; esclarecer os processos de estresse; avaliar a eficácia de propostas de intervenção de professores focadas na redução de estresse (KYRIACOU, 2001b, tradução nossa).

Para Kyriacou (1981, p. 55): “O estresse ocupacional pode ser definido como um estado emocional desagradável (por exemplo, tensão, frustração, ansiedade, exaustão emocional) decorrentes de aspectos do trabalho". A partir de pesquisas do autor sobre ações de enfrentamento por parte de 42 professores. O autor concluiu que as três ações mais relatadas foram "tentar manter as coisas em perspectiva", "tentar evitar confrontos" e "tentar relaxar depois do trabalho" (KYRIACOU, 1981). Ao analisar os componentes principais das ações, Kyriacou (1981, p. 59) observou que algumas das ações pareciam relacionar-se com o "apoio social", de modo que, este pode "ser visto como subjacente a toda gama de ações de enfrentamento, e o importante é que os diferentes tipos de apoio social estão disponíveis em uma escola".

Sobre o estresse ocupacional em professores brasileiros, estudos têm encontrado evidências de relação entre as condições de trabalho e ocorrência de estresse (CLARO, 2009; ALTOÉ, 2010; LIMA, 2011; MENDES, 2011; NEVES, 2014). Silveira et al (2014), em estudo com professores regentes de classes de alunos com deficiência do Ensino Fundamental de escolas públicas de Vitória/ES, verificaram que a grande quantidade de alunos e seus problemas comportamentais foram os estressores mais relatados pelos professores. A sobrecarga de serviço e percepção da pouca preocupação governamental foram relacionadas aos aspectos da educação inclusiva. A variável inclusão de alunos portadores de deficiência foi a menos citada, evidenciando que não é essa a causa central para o estresse do professor. 


\section{Revista Triângulo}

ISSN 2175-1609

Kyriacou e Chien (2004), ao investigarem professores de Taiwan, verificaram que estes avaliaram a profissão como muito ou extremamente estressante, sendo que as mudanças nas políticas educacionais e a carga de trabalho foram indicadas como as principais fontes de estresse. Concluíram os autores que esses resultados se assemelham a estudos realizados no mundo ocidental.

Considerando as condições de trabalho do professor como variáveis para o surgimento de estresse ocupacional e a importância das estratégias de enfrentamento como processos de prevenção e intervenção, o presente estudo comparou a presença de estresse ocupacional e as estratégias de enfrentamento de professores do ensino fundamental de Vitória/ES e professores da rede de educação profissional de Cuiabá/MT.

\section{MATERIAIS E MÉTODOS}

O estudo foi desenvolvido a partir de delineamento descritivo com a finalidade de identificar estresses e estressores em duas amostras de professores da rede pública de ensino de dois estados da federação brasileira.

Os participantes foram 109 professores de escolas do Ensino Fundamental público do Espírito Santo (101 mulheres; Média de idade = 35,66 anos; Desvio padrão $=9,66)$ e 81 professores ( 55 mulheres; Média de idade $=51,24$ anos; Desvio padrão $=8,06$ ) pertencentes a uma instituição federal de Educação Profissionalizante de Cuiabá/MT.

Para a coleta de dados foram utilizados os seguintes instrumentos:

a) Questionário de caracterização da amostra;

b) Escala de Estresse no Trabalho Docente (EETD) - Stress at Work Checklist desenvolvida por Kyriacou (2000) foi traduzida e adaptada por Silveira (2014). Essa escala contém 10 itens com atenção a sintomas ligados ao estresse no trabalho comumente indicados por professores. A escala varia de 0 a 3 ( 0 = nunca sinto; $1=$ alguns dias; $2=$ na maioria dos dias; $3=$ todos os dias). Há a indicação de alto grau de estresse ocupacional em escores superiores a 15. Exemplos de situações: a) Eu estou preocupado em decorrência de problemas no trabalho; b) Sinto que o trabalho está afetando a minha vida profissional; c) Ao final do dia na escola, sinto-me emocionalmente exausto;

c) Escala de Coping para Professores: desenvolvido por Kyriacou e Chien (2004). Essa escala contém 25 itens sobre comportamentos de coping ou enfrentamento de possíveis situações estressantes encontradas por professores. $\mathrm{O}$ instrumento foi traduzido e adaptado 


\section{Revista Triângulo}

ISSN 2175-1609

transculturalmente por Silveira et al. (2014b) se constituindo como parte do Questionnaire Taiwanese Primary School Teachers' Stress and Coping Strategies. Para o preenchimento, é necessário que o participante aponte a frequência da eficácia percebida "o quanto é efetivo" para cada comportamento na redução do estresse e a frequência com que manifesta cada comportamento listado "o quanto você tem praticado". A escala varia de 1 a 5 (1= não efetivos ou sem uso; $2=$ poucos efetivos; $3=$ moderadamente efetivos; $4=$ efetivos; 5= extremamente efetivos). Exemplo de estratégias: a) Discutir com colegas e amigos; b) Iniciar a aula com regras claramente definidas e expectativas; c) Relaxar após o trabalho.

Nos dois estados, a coleta ocorreu após autorização do Comitê de Ética em Pesquisa em Mato Grosso (HUJM/UFMT - $n^{\circ}$ 130930) e no Espírito Santo (UFES no 264-11). Os instrumentos foram aplicados pelos próprios pesquisadores. Os dados foram analisados de forma descritiva com uso do programa estatístico Statistical Package For The Social Science (SPSS) 18.0.

\section{ANÁLISE DOS DADOS E RESULTADOS}

Em relação à percepção de estresse analisado pela Escala de Estresse no Trabalho Docente, verificou-se que foi maior o percentual de professores que não indicaram presença de estresse (Tabela 1).

Tabela 1 - Percepção de estresse na Escala de Estresse no Trabalho Docente, por professores de Mato Grosso e Espírito Santo $(\mathrm{N}=190)$

\begin{tabular}{l|cc}
\hline \multirow{2}{*}{ Estados } & \multicolumn{2}{|c}{ Estresse } \\
\cline { 2 - 3 } & Sim & Não \\
\hline Espírito Santo & $17(15,6 \%)$ & $92(84,4 \%)$ \\
Mato Grosso & $12(14,8 \%)$ & $69(85,2 \%)$ \\
\hline
\end{tabular}

Diferentemente dos resultados de estudos brasileiros (LIMA, 2011; MENDES, 2011), nas duas amostras, a ausência de estresse obteve maior percentual, ou seja, professores da rede de ensino público e professores da rede de educação profissional, diante da expansão da Rede Federal de Educação Profissional, Científica e Tecnológica (RFEPCT), em sua maioria, não indicaram presença de estresse. Esses resultados aproximam-se de outros estudos brasileiros com diferentes profissionais. A esse respeito, Oliveira e Cardoso (2011) 


\section{Revista Triângulo}

ISSN 2175-1609

investigaram professores da área de saúde de universidades públicas e verificaram que apenas $24,2 \%$ dos participantes apresentaram sinais clínicos de estresse, embora tenham relatado perceberem o trabalho e a si mesmos estressados. Silveira et al (2014) observaram a presença de sintomas de estresse em mais da metade da amostra de conveniência, composta por professoras de educação inclusiva com alunos com necessidades educativas especiais em sala.

Também vale ressaltar a presença de percepção do trabalho como fonte de prazer e satisfação, conforme retrata Mendes (2011), ao constatar que educadores do ensino fundamental do município de Porto Alegre demonstraram clareza ao identificar elementos que causam mal-estar, porém, com presença da crença sobre o seu trabalho enquanto mola propulsora para a construção de uma sociedade melhor.

Souza e Araujo (2015), ao investigarem estresse e fatores de resiliência em 92 profissionais da área da saúde de diferentes categorias, constataram que mais da metade dos participantes apresentou baixo estresse ocupacional e controle sobre a atividade laboral. Assim, o menor percentual de percepção para a presença de estresse pode estar relacionado a fatores de controle sobre os indicadores de estresse e, desse modo, sobre a atividade laboral e à presença efetiva de uma rede de apoio social.

No que se refere às estratégias de enfrentamento avaliadas pela Escala de Coping para Professores, verificou-se nas duas amostras, proximidades e diferenças nos comportamentos em termos de "o quanto é efetivo" e "o quanto você tem praticado". Considerando que a Escala apresenta 25 situações, na Tabela 2, serão apresentados os resultados apenas das estratégias em que se verificaram diferenças significativas.

Tabela 2 - Diferenças significativas para os professores do Espírito Santo e Mato Grosso na Escala de Coping para Professores "o quanto é efetivo" e "o quanto tem praticado" $(\mathrm{N}=190)$

\begin{tabular}{|c|c|c|c|}
\hline Coping & Média & DP & $p$ \\
\hline & MT ES & MT ES & MT ES \\
\hline $\begin{array}{l}\text { Iniciar aulas com regras claramente } \\
\text { definidas }\end{array}$ & & & \\
\hline
\end{tabular}




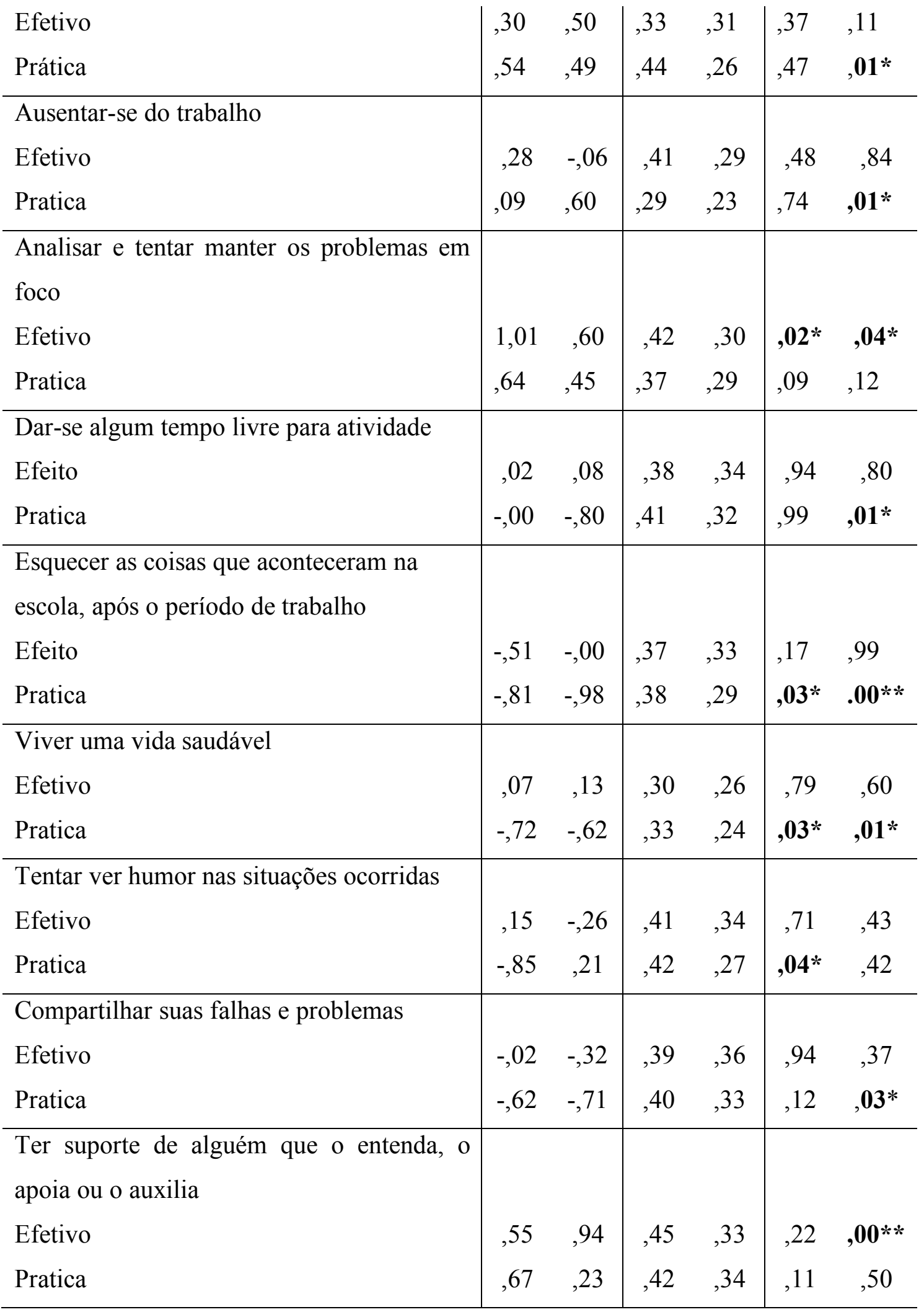

Legenda: MT= Mato Grosso; ES= Espírito Santo; M= Média; DP: Desvio Padrão; Teste de T Pareado $\left(p \geq 0,05^{*} ; p \geq 0,01 * *\right)$ 


\section{Revista Triângulo}

ISSN 2175-1609

De acordo com a Tabela 2, verificou-se a presença de diferenças significativas em comum para algumas estratégias de coping nas duas amostras (ES e MT), para o "quanto é efetivo" e "o quanto tem praticado". As estratégias significativas que evidenciaram o quanto tem praticado, foram: a) Esquecer as coisas que aconteceram na escola, após o período de trabalho $\left(\mathrm{MT}=, 03 * ; \mathrm{ES}=, 00^{* *}\right)$, principalmente para os professores do estado do ES e, b) Viver uma vida saudável $(\mathrm{MT}=, 03 * ; \mathrm{ES}=, 01 *)$. Outro resultado significativo foi em relação ao uso da estratégia considerada o quanto é efetivo, sendo esta "Analisar e tentar manter os problemas em foco" (MT=,02*; ES=,04*).

A similaridade para as duas amostras de professores do ensino fundamental público do Espírito Santo e professores da educação profissionalizante de Mato Grosso, pode estar relacionada à similaridade nas condições de trabalho vivenciadas pelos professores. Em outras palavras, a expansão da rede profissionalizante federal provocou aumento do número de alunos, implantação de diferentes modalidades de ensino, rapidez das mudanças das políticas requerendo processo de adaptação por parte dos professores.

Ao comparar os resultados dos dois estados, averiguou-se que os professores do Espírito Santo apresentaram mais estratégias significativas. Em termos do quanto tem praticado as estratégias foram: a) Iniciar a aula com regras claramente definidas e expectativas $\left(, 01^{*}\right)$; b) Ausentar-se do trabalho $\left(, 01^{*}\right)$; c) Dar-se algum tempo livre para atividades de interesse $\left(, 01^{*}\right)$; d) Compartilhar suas falhas e problemas $(, 03 *)$. Em relação ao quanto é efetivo apenas a estratégia Ter suporte de alguém que o entende, o apoia e o auxilia $\left(, 001^{* *}\right)$ foi significativa. Observa-se que as estratégias significativamente referenciadas pelos professores do Espírito Santo abarcam comportamentos mais individuais, assim como comportamentos que expressam apoio social, principalmente, em relação à efetividade da estratégia, mais do que à prática. $\mathrm{O}$ apoio social é percebido como efetivo para esses professores. Para a amostra de professores de Mato Grosso, comparativamente, a estratégia com resultado significativo referiu-se ao quanto tem praticado foi a seguinte ação: Tentar ver humor nas situações ocorridas $(, 04 *)$.

De modo geral, verificou-se que para os professores, a prática de algumas estratégias se mostra mais efetiva que, simplesmente, a percepção em relação ao efeito da mesma, ou seja, é mais efetivo praticar, principalmente para os professores da rede pública de ensino do Espírito Santo. Em termos de práticas de estratégias, as que requerem ação individual se 


\section{Revista Triângulo}

ISSN 2175-1609

fizeram presentes (esquecer as coisas, tentar ver humor, ausentar-se do trabalho, etc.), assim como estratégias de apoio social (viver uma vida saudável, tentar suporte de alguém).

Comparando os resultados encontrados com o estudo de Kyriacou e Chien (2004) com 203 professores de escolas primárias de Taiwan, usando o mesmo instrumento, as ações de enfrentamento em comum foram: ter uma vida saudável, ter suporte de alguém que o entenda, o apoia e o auxilia e tentar ver humor nas situações ocorridas.

Ao comparar os professores das amostras, em relação à presença de estresse, verificaram-se diferenças significativas entre a maioria das estratégias, incluindo "o quanto é efetivo" e "o quanto tem praticado". A Tabela 3 apresenta apenas as estratégias que apresentaram diferença significativa.

Tabela 3 - Comparação das médias na Escala de Coping do Trabalho Docente em relação aos professores sem e com estresse

\begin{tabular}{|c|c|c|c|c|c|c|}
\hline \multirow[t]{2}{*}{ Coping } & \multicolumn{3}{|c|}{$\begin{array}{c}\text { Professores sem } \\
\text { estresse } \\
(\mathrm{N}=161)\end{array}$} & \multicolumn{3}{|c|}{$\begin{array}{l}\text { Professores com } \\
\text { estrese }(\mathrm{N}=29)\end{array}$} \\
\hline & M & $\mathrm{DP}$ & $p$ & M & $\mathrm{DP}$ & $p$ \\
\hline Discutir seus problemas com colegas & , 16 & ,88 &, $01^{*}$ & ,03 & 1,28 & ,88 \\
\hline Relaxar após o trabalho & ,47 & 1,31 &, $00 * *$ &, 61 & 1,96 & 11 \\
\hline Ausentar-se do trabalho &, 33 & 1,26 &, $00 * *$ &, 03 & 1,29 &, 88 \\
\hline $\begin{array}{l}\text { Aconselhamento psicológico } \\
\text { Assegurar-se de que você entende a } \\
\text { melhor forma de ensinar conteúdos }\end{array}$ &, 58 & 1,38 &, $00 * *$ & 1,33 & 1,83 &, $00 * *$ \\
\hline planejados &, 17 &, 80 &, $00 * *$ &, 81 &, 55 & ,09 \\
\hline $\begin{array}{l}\text { Dar-se algum tempo livre para } \\
\text { atividades de interesse }\end{array}$ & ,41 & 1,11 &, $00 * *$ & 1,00 & 301 & $00 * *$ \\
\hline $\begin{array}{l}\text { Tentar conhecer mais sobre seus alunos } \\
\text { em suas especificidades, como }\end{array}$ & & & & & & \\
\hline indivíduos &, 27 & ,99 &, $00 * *$ &, 59 & ,88 &, $00 * *$ \\
\hline $\begin{array}{l}\text { Comunicar-se com os pais, em mais } \\
\text { tempo e em mais ocasiões }\end{array}$ & ,41 & 1,18 &, $00 * *$ &, 37 & 1,54 & ,22 \\
\hline Pensar nas próximas férias &, 16 & ,93 &, $02 *$ &, 44 & 1,25 &, 07 \\
\hline
\end{tabular}




\section{Revista Triângulo}

ISSN 2175-1609

\section{Ficar sozinho}

Esquecer as coisas que aconteceram na escola

Viver uma vida saudável

Aprender a como controlar a emoção

Tentar ver humor nas situações de confronto

Evitar situações de confronto

Participar de educação continuada

Compartilhar suas falhas e problemas

Ter suporte de alguém que o entenda

Planejar o futuro e priorizar as metas

Ler livros sobre stress

\begin{tabular}{|c|c|c|c|c|c|}
\hline, 00 & 1,03 & ,98 &, 51 & 1,19 &, $03^{*}$ \\
\hline, 30 & 1,05 &, $00 * *$ & ,96 & 1,62 &, $00 * *$ \\
\hline, 56 & 1,01 &, $00 * *$ & 1,33 & 1,46 &, $00 * *$ \\
\hline, 28 & ,90 &, $00 * *$ & 1,03 & 1,42 &, $00 * *$ \\
\hline ,30 & 90 &, $00 * *$ &, 76 & 1,24 &, $00 * *$ \\
\hline 1,23 & 1,90 &, $00 * *$ & 1,42 & 1,87 &, $00 * *$ \\
\hline, 20 & 1,13 &, $02 *$ & ,29 & 1,03 &, 14 \\
\hline, 40 & ,93 &, $00 * *$ & ,64 & 1,25 &, $01 *$ \\
\hline, 43 & 1,02 &, $00 * *$ & ,94 & 1,74 &, $00 * *$ \\
\hline, 25 & ,93 &, $00 * *$ &, 55 & 1,50 &, 06 \\
\hline, 37 & ,94 &, $00 * *$ &, 74 & 1,34 &, $00 * *$ \\
\hline
\end{tabular}

Legenda: $\mathrm{M}=$ Média; DP: Desvio padrão; Teste de T Pareado $\left(p \geq 0,05^{*} ; p \geq 0,01^{* *}\right)$

$\mathrm{Na}$ Tabela 3 observa-se que, em relação aos professores que indicaram ausência de estresse, houve diferença significativa na maioria $(n=20)$ das estratégias em relação à percepção de efetividade das situações e à prática das mesmas. Já aos professores que apresentaram presença de estresse, foram bem específicas as situações em que a efetividade e a prática apresentam diferenças significativas, sendo: Aconselhamento psicológico; Dar-se algum tempo livre para atividades de interesse; Tentar conhecer mais sobre seus alunos em suas especificidades, como indivíduos; Ficar sozinho; Esquecer as coisas que aconteceram na escola; Viver uma vida saudável; Aprender a como controlar a emoção; Tentar ver humor nas situações de confronto; Evitar situações de confronto; Compartilhar suas falhas e problemas; Ter suporte de alguém que o entenda; Ler livro sobre estresse.

De acordo com Kyriacou (2001 apud KYRIACOU; CHIEN, 2004, p. 91), as estratégias podem ser de dois tipos, as “(...) de ação direta, que lidam com ações tomadas para reduzir a fonte de estresse; e estratégias paliativas, que envolvem alívio e/ou controle emocional". A partir dessa classificação pode-se observar a presença de estratégias paliativas para os professores que não indicaram estresse, quando comparadas aos professores com indicação de estresse. Em relação à estratégia "Aprender a controlar a emoção", os autores 


\section{Revista Triângulo}

ISSN 2175-1609

salientam que tem sido uma estratégia fortemente defendida em países ocidentais (KYRIACOU, 2000 apud KYRIACOU; CHIEN, 2004).

Silveira (2014), ao investigar as estratégias de coping de professoras da educação inclusiva do município de Vitória através da Teoria Motivacional do Coping, observou maior frequência de estratégias adaptativas do que mal-adaptativas. As professoras com indicação de estresse apresentaram com maior frequência estratégias como submissão, resolução de problema e acomodação.

As situações em que não houve diferença para os dois grupos e que, portanto, foram consideradas pouco efetivas e praticadas foram: Iniciar aulas com regras claramente definidas; Analisar e tentar manter os problemas em foco; Respirar fundo; Praticar algum ato ou pensamento religioso; Mudar sua escola. Esses resultados mostram que estratégias que focam no problema são menos consideradas pelos professores, assim como estratégias de coping religioso e ações físicas.

\section{CONSIDERAÇÕES FINAIS}

O estudo envolvendo professores de dois estados brasileiros abordando estresse e estratégias de enfrentamento, foi realizado com professores do ensino fundamental e da educação profissional. De modo geral, foi menor o percentual de professores com indicação de estresse para o trabalho docente nas amostras, se diferenciando de alguns estudos da área, assim como, percebeu-se proximidade com outras investigações. Esse resultado evidencia a necessidade de outras investigações em relação ao estresse, considerado um construto que abarca diferentes dimensões.

Em relação às estratégias de coping, verificou-se o uso comum de algumas estratégias nas duas amostras, embora os níveis de atuação sejam diferentes, esses resultados demonstram que o contexto de trabalho desses professores requer o uso das mesmas estratégias. Os professores do ensino fundamental público do Espírito Santo apresentaram mais estratégias que os da educação profissional de Mato Grosso, possivelmente em função das condições de trabalho vivenciadas por esses professores.

Comparativamente, os professores que não apresentaram indicativos de estresse apresentaram mais estratégias de coping paliativas, ou seja, menos focadas para a direção do problema. Por outro lado, em relação às cinco estratégias que não tiveram resultados significativos tanto para a presença como à ausência de estresse, três delas (iniciar aulas com 
Revista Triângulo

ISSN 2175-1609

regras claramente definidas, analisar e tentar manter os problemas em foco e mudar sua escola) são estratégias de ações diretas voltadas para a redução do estresse.

\section{REFERÊNCIAS}

ALDWIN, C. M. Stress, coping e development: an integrative perspective. Second Edition, Guilford Press, New York, 2007.

ALTOÉ, A. Políticas institucionais e seus desdobramentos sobre o trabalho docente: absenteísmo e presenteísmo. 2010. 138 p. Dissertação (Mestrado em Educação) - Pontifícia Universidade Católica de Minas Gerais, Belo Horizonte, 2010.

CARLOTTO, M. S. A síndrome de burnout e o trabalho docente. Psicologia em Estudo, v. 7, n. 1, p. 21-29, 2002.

CLARO, G. R. A Saúde Mental do Professor do Ensino Fundamental em Curitiba.2009. 135 p. Dissertação (Mestrado em Educação) - Universidade Tuiuti do Paraná, Curitiba, 2009.

CONFEDERAÇÃO NACIONAL DOS TRABALHADORES EM EDUCAÇÃO. Síndrome da exaustão persistente em educadores. 2008. Disponível em: http://cnte.org.br/index.php/comunicacao/noticias/859-sindrome-da-exaustao-persiste-entreeducadores.html. Acesso em: 25 de fevereiro, 2016.

FERREIRA, R. C.; SILVEIRA, A. P.; SÁ, M. A. B.; FERES, S. B. L.; SOUZA, J. G. S.; MARTINS, A. M. E. B. L. Transtorno mental e estressores no trabalho entre professores universitários da área da saúde. Trabalho, Educ. Saúde, v. 13, supl. 1, p. 135-155, 2015.

KYRIACOU, C. Stress-busting for teachers. Cheltenham: Stanley Thornes, 2000.

KYRIACOU, C. Teacher stress: Directions for future research. Educational Review, v. 53, n. 1, p. 27-35, 2001.

KYRIACOU, C. Social Support and Occupational Stress among Schoolteachers. Educational Studies, v. 7, n. 1, p. 55-60, 1981.

KYRIACOU, C.; CHIEN, P. Teacher stress in Taiwanese primary schools. Journal of Educational Enquiry, University of South Australian v. 5, n. 2, p. 86-104, 2004.

LIMA, E. C. Os sentimentos do professor gerados pelas suas vivências na prática docente: um estudo com docentes em uma escola pública no Piaúi.2011. Dissertação. (Mestrado em Psicologia) - Universidade de Fortaleza, Fortaleza, 2011.

MAUES, O.C.; MOTA JUNIOR, W.P. da. A nova regulação educacional e o trabalho docente na pós-graduação brasileira. Linhas Críticas, Brasília, DF, v.17, n.33, p.385-402, 2011. 
MENDES, A. R.Saúde docente: uma realidade detectada - em direção ao bem-estar e a realização profissional.2011. Dissertação. (Mestrado em Educação) - Pontifícia Universidade Católica do Rio Grande do Sul, Porto Alegre, 2011.

MOTA, V. M. C. O exercício da docência e a preservação da saúde mental do professor: um estudo a partir de suas condições de trabalho e existência. 2011. 132p. Dissertação (Mestrado em Psicologia) - Universidade Federal de Minas Gerais - Belo Horizonte, 2011.

NEVES, M. S. Trabalho docente e estresse: um estudo com professores do IFMT - Cuiabá. 2014. 180p. Dissertação (Mestrado em Educação) - Universidade do Estado de Mato Grosso, Cáceres, 2014.

NODARI, N. L.; FLOR, S. R. A.; RIBEIRO, A. S.; HAYASIDA, N. M. A.; CARVALHO, G. J. R. Estresse, conceitos, manifestações e avaliação em saúde: revisão de literatura. Revista Saúde e Desenvolvimento Humano, v. 2, n. 1, p. 61-74, 2014.

OLIVEIRA, D. A. A reestruturação do trabalho docente: precarização e flexibilização. Educ. Soc., v. 25, n. 89, p. 1127-1144, 2004.

OLIVEIRA, M. G. M.; CARDOSO, C. L. Stress e trabalho docente na área de saúde. Estudos de Psicologia, v. 28, n. 2, p. 135-141, 2011.

RAMOS, F. P.; ENUMO, S. R. F. PAULA, K. M. P. Teoria Motivacional do Coping: uma proposta desenvolvimentista de análise do enfrentamento do estresse. Estudos de Psicologia, v. 32, n. 2, p. 269-279, 2015.

SANTOS, G. B. Os professores e seus mecanismos de fuga e enfrentamento. Trabalho, Educ. Saúde, v. 7, n. 2, p. 285-304, 2009.

SILVA, M. G. M. Trabalho Docente na Pós-Graduação: a lógica da produtividade em questão. 2008. 232p. Tese (Doutorado em Educação). Universidade Federal do Rio Grande do Sul - UFRGS, Porto Alegre, 2008.

SILVEIRA, K. A.; ENUMO, S. R. F.; POZZATTO, R. N. PAULA, K. M. P. Indicadores de estresse e coping no contexto da educação inclusiva. Educ. Pesqui., v. 40, n. 1, p. 127-142, 2014.

SILVEIRA, K. A. A promoção do engajamento discente por professoras de classe inclusiva e suas relações com processo de estresse e coping docente. 2014. 216p. Tese (Doutorado em Psicologia) Universidade Federal do Espírito Santo, Vitória, 2014.

SKINNER, H. A, EDGE, K., ALTMAN, J., \& SHERWOOD, H. Searching for the structure of coping: A review and critique of category systems for classifying ways of coping. Psycological Bulletin, v. 129, n. 2, p. 216-269, 2003. 
Revista Triângulo

ISSN 2175-1609

SOUSA, A. M. de. O perfil do adoecimento docente na Universidade de Brasília de 2006 a 2011.2013. 103 p. Dissertação (Mestrado em Ciências da Saúde) - Universidade de Brasília, Brasília, 2013.

SOUZA, V. F. S.; ARAUJO, C. C. F. Estresse ocupacional e resiliência entre profissionais da saúde. Psicologia: Ciência e Profissão, v. 35, n. 3, p. 900-915, 2015.

VIANA, C. M. Q. Q.; MACHADO, L. C. Desenvolvimento profissional docente e intensificação do trabalho: viver ou sobreviver. Em Aberto, v. 29, n. 97, p. 47-60, 2016.

VIEIRA, J.S.; GONÇALVES, V. B.; MARTINS, M. F. D. Trabalho docente e saúde das professoras da Educação Infantil de Pelotas, Rio Grande do Sul. Trabalho, Educ. Saúde, v. 14, n. 2, p. 559-574, 2016.

Citações:

1- "Na medida em que entendemos melhor este fenômeno psicossocial como processo, identificando suas etapas e dimensões, seus estressores mais importantes, seus modelos explicativos, podemos vislumbrar ações que permitam prevenir, atenuar ou estancar (...)" (CARLOTTO, 2002, p. 27).

2- Em recente revisão sistemática da literatura sobre o estresse entre os anos de 1959 a 2014 Nodari et al (2014, p. 61) verificaram uma “(...) influência multifatorial no padrão e na magnitude das respostas ao estresse, com predomínio nas manifestações de sintomas psicológicos".

3- Nessa perspectiva numa abordagem mais recente sobre o estresse Aldwin (2007, p. 24) enfatiza que “(...) estresse se refere àquela qualidade de experiência, produzida por uma transação pessoa-ambiente, que, através tanto da excitação ou recrudescimento, resultam em estresse psicológico ou fisiológico".

4- Recentemente Ramos et al (2015, p. 270) apresentou as três grandes abordagens sobre o coping, sendo "(a) coping como estilos hierárquicos e centrados em mecanismos de defesa e estilos de personalidade, em uma abordagem psicodinâmica; (b) coping como processo de interação indivíduo-ambiente ou perspectiva cognitiva do coping (...)".

5- A segunda abordagem tem como precursor o estudo de R. S. Lazarus com a obra "Psychological Stress and Coping Process" no ano de 1966, na qual o coping é compreendido “(...) como um processo resultante de uma transação entre o indivíduo e o ambiente, buscando seus determinantes situacionais e cognitivos” (RAMOS et al, 2015, p. 271).

6- A última abordagem “(...) (c) coping como ação regulatória, em uma perspectiva desenvolvimentista” (RAMOS et al., 2015, p. 270).

7- Nessa teoria de acordo com Ramos et al $(2015$, p. 272) "O coping é desencadeado, para a TMC, quando uma dada experiência é percebida pelo sujeito como ameaça ou desafio a alguma de suas necessidades psicológicas básicas ou a várias delas (...)". 8- Com base em teóricos da área sobre estresse ocupacional Souza e Araujo $(2015$, p. 92) esclarecem que estresse ocupacional “(...) pode ser compreendido como um complexo processo em que o trabalhador busca responder a demandas que ultrapassam as possibilidades de adaptação individual e social, desencadeando-se transtornos no plano biológico e/ou comportamental".

9- Para Kyriacou (1981, p. 55) “O estresse ocupacional pode ser definido como um estado emocional desagradável (por exemplo, tensão, frustração, ansiedade, exaustão emocional) decorrentes de aspectos do trabalho".

10- Ao analisar os componentes principais das ações, Kyriacou (1981, p. 59) observou que algumas das ações pareciam relacionarse com o "apoio social”, de modo que, este pode “(...) ser visto como subjacente a toda gama de ações de enfrentamento. E o importante é que os diferentes tipos de apoio social estão disponíveis em uma escola (...)”. 